\title{
The development and pilot testing of the Self-management Programme of Activity, Coping and Education for Chronic Obstructive Pulmonary Disease (SPACE for COPD)
}

\author{
This article was published in the following Dove Press journal: \\ International Journal of COPD \\ 8 July 2013 \\ Number of times this article has been viewed
}

\author{
Lindsay D Apps' \\ Katy E Mitchell' \\ Samantha L Harrison' \\ Louise Sewell' \\ Johanna E Williams' \\ Hannah ML Young' \\ Michael Steiner' \\ Mike Morgan' \\ Sally J Singh ${ }^{1,2}$ \\ 'National Institute of Health \\ Research CLAHRC-LNR Pulmonary \\ Rehabilitation Research Group, \\ University Hospitals of Leicester \\ NHS, Leicester, UK; ${ }^{2}$ Applied \\ Research Centre, Health and \\ Lifestyle Interventions, Coventry \\ University, Coventry, UK
}

Purpose: There is no independent standardized self-management approach available for chronic obstructive pulmonary disease (COPD). The aim of this project was to develop and test a novel self-management manual for individuals with COPD.

Patients: Participants with a confirmed diagnosis of COPD were recruited from primary care.

Methods: A novel self-management manual was developed with health care professionals and patients. Five focus groups were conducted with individuals with COPD $(\mathrm{N}=24)$ during development to confirm and enhance the content of the prototype manual. The Self-management Programme of Activity, Coping and Education for Chronic Obstructive Pulmonary Disease (SPACE for COPD) manual was developed as the focus of a comprehensive self-management approach facilitated by health care professionals. Preference for delivery was initial face-to-face consultation with telephone follow-up. The SPACE for COPD manual was piloted with 37 participants in primary care. Outcome measures included the Self-Report Chronic Respiratory Questionnaire, Incremental Shuttle Walk Test, and Endurance Shuttle Walking Test (ESWT); measurements were taken at baseline and 6 weeks. Results: The pilot study observed statistically significant improvements for the dyspnea domain of the Self-Report Chronic Respiratory Questionnaire and ESWT. Dyspnea showed a mean change of 0.67 (95\% confidence interval $0.23-1.11, P=0.005)$. ESWT score increased by 302.25 seconds (95\% confidence interval 161.47-443.03, $P<0.001)$.

Conclusion: This article describes the development and delivery of a novel self-management approach for COPD. The program, incorporating the SPACE for COPD manual, appears to provoke important changes in exercise capacity and breathlessness for individuals with COPD managed in primary care.

Keywords: self-management, primary care, Self-Report Chronic Respiratory Questionnaire, dyspnea, Endurance Shuttle Walking Test

\section{Introduction}

It is now accepted that patients with chronic conditions should be fully involved in their care and also participate in decisions about their own management. Selfmanagement strategies have been described in many long-term conditions ${ }^{1,2}$ and have been applied to patients with chronic obstructive pulmonary disease (COPD). ${ }^{3-6}$ However, the literature in this field offers little consistency with regard to the structure or effectiveness of self-management programmes. ${ }^{7}$ Further, it is not known at what
Correspondence: Lindsay D Apps Pulmonary Rehabilitation, University Hospitals of Leicester NHS Trust, Groby Road, Leicester, LE3 9QP, UK Tel +44 II6 2583 I8I

Fax +441162583149

Email lindsay.d.apps@uhl-tr.nhs.uk 
stage in the disease self-management techniques should be introduced. ${ }^{7}$ To date, most self-management programs have focused on the amelioration of acute exacerbations and admission avoidance by including action plans. ${ }^{5,8-10}$ While this is a reasonable ambition, it may not have a lasting effect or even achieve the intended aims if the patients have not undergone behavior change or lack the confidence to contribute to their own management.

The principles of self-management programs in chronic disease have been established in terms of content but not necessarily in mode of delivery. ${ }^{11}$ Self-management programs should aim to promote physical activity, smoking cessation, management of social interactions, medicines management, and the ability to recognize and respond to symptoms. Delivery of effective self-management skills requires the patient to have an acceptance of behavior change. This means that the programs need to be structured to develop knowledge and skills and to address attitudes to change, so the patient can achieve the necessary behavior change. ${ }^{12}$ One approach is social cognitive techniques that aim to equip the patient with core skills including in problem solving, decision making, resource utilization, formation of patient-provider partnerships, and taking action. ${ }^{11}$ Health professionals may also need further education about how to support patients with self-management strategies and foster positive behavior change. ${ }^{12}$ One such technique is motivational interviewing, which is focused on resolving ambivalence toward lifestyle changes and enhancing motivation for behavior change. ${ }^{13}$

The self-management literature in COPD reports limited success in achieving these aims. ${ }^{7}$ The structures of reported programs vary. In some cases they are similar to conventional pulmonary rehabilitation programs, ${ }^{3,6,14,15}$ while others simply provide educational literature and action plans for exacerbations. ${ }^{8,9,16,17}$ To date, the most effective program, described in Canada, is a large-scale operation that merges home-based rehabilitation and case management. ${ }^{5}$ The most obvious feature of successful self-management programs is that they involve an element of infrastructure support provided by the health professional. ${ }^{3,5,12}$ Obviously, such programs incur large costs and clearly do not involve the patient being left to fend for themselves. Since, at the other end of the self-management spectrum, simply giving patients educational materials is unlikely to be effective, there is a role for a self-management program that can achieve education and behavior change without requiring expensive infrastructure support. One such approach would be to develop a standardized and comprehensive educational manual and introduce the content with motivational interviewing techniques to ensure that it achieves the dual aim of providing self-management skills and facilitating the associated behavior change. Thus, this paper describes the development and preliminary testing of a self-management manual (the Self-management Programme of Activity, Coping and Education for Chronic Obstructive Pulmonary Disease [SPACE for COPD] manual, or SPACE manual) designed to be introduced to patients through the vehicle of a motivational interview.

\section{Methods}

This section first describes the development of the SPACE manual, including findings from focus groups (FGs) conducted during the development phase, then the pilot testing of the effectiveness of the approach. The process followed in developing and testing the manual is outlined in Figure 1.

\section{Study population}

Participants in this study all had COPD. They were divided into two groups: the first group attended FGs during the development phase of the manual and the second group was involved in a pilot study of the final intervention.

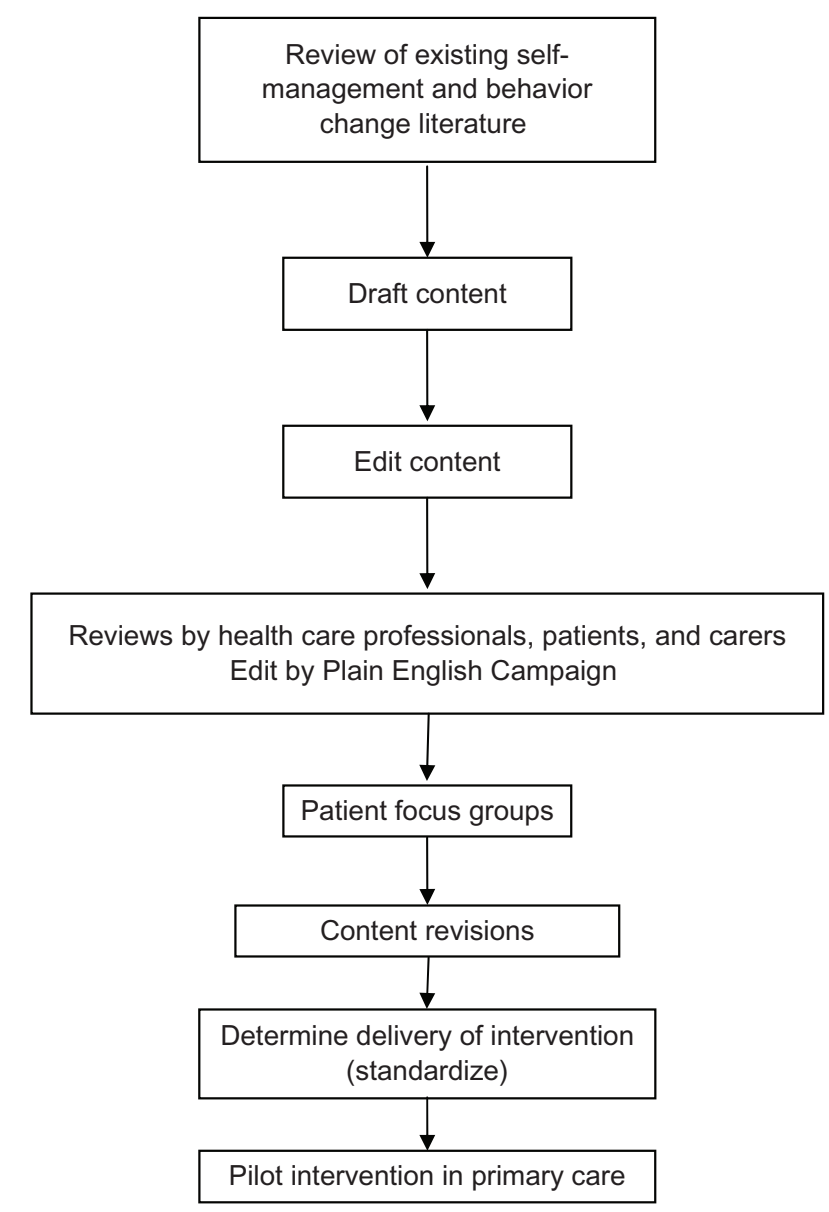

Figure I Process of manual development and testing. 


\section{Ethics}

The study was approved by the Nottingham 2 Local Research Ethics Committee.

\section{Development of SPACE for COPD Construction of SPACE for COPD}

The process followed in developing the self-management program is outlined in Figure 1. Central to the delivery of this supported self-management program was the development of the manual for patients to work through. The manual development process involved individuals with COPD, their caregivers, and health care professionals with experience of COPD, and encompassed the management of COPD at all stages of severity.

First, the literature on COPD self-management and behavior change was reviewed. Searches of MEDLINE ${ }^{\circledR}$, Embase, CINAHL, BNI ${ }^{\mathrm{TM}}$, and PsycINFO ${ }^{\circledR}$ databases were performed to locate the relevant research using the following search terms: "educat*" or "self-manag*" or "self manag*" or "self-car"" or "self car" or "train*" or "instruct*" or "patient cent*" or "patient-cent*" or "patientfocus*" or "patient focus*" or "patient-education" or "patient education" or "management plan*" or "management program*" and "COPD."

The initial development of the manual acknowledged the work of Lorig and Holman ${ }^{11}$ and was mindful of a breadth of content to extend beyond exacerbation management. ${ }^{18}$ The pulmonary rehabilitation team, patients, and health care professionals with expertise in particular topics were involved in the initial development of the content and this was further refined through collaboration with professionals and patients.

After several editing rounds with health care professionals and patients, content was drafted containing structured educational content and interactive tasks to facilitate learning of self-management skills. This was developed into a manual for patients to work through independently at home with the support of a health care professional. An action plan for proactive exacerbation recognition and management was also proposed for incorporation into the program.

Once a draft manual was developed, FGs were conducted to review the manual content and determine preferences for the delivery of such a program based around a manual to support self-management.

\section{Focus groups}

Five FGs were held, facilitated by two researchers with experience in qualitative methods (LDA, SLH). A convenience sample of individuals with COPD was recruited from pulmonary rehabilitation (PR) (Table 1) and this included patients who had completed and discontinued PR. Patients in this group had experience of exercise and were able to provide an evaluation of education they had already received and comment on how this could be extended. This also aided group cohesiveness, as members of the FG had a common experience to draw upon.

The FG schedule was structured to ensure new topics could arise; minor revisions were made to it after the first two FGs. Participants were asked to comment on what information was needed to self-manage their COPD, their preferred level of support from health care professionals and how SPACE for COPD could be facilitated. Toward the end of the discussion, draft content for the SPACE for COPD manual was presented and action plans discussed.

Written informed consent was obtained from participants and all FGs were digitally recorded and transcribed verbatim.

Data were analyzed thematically, ${ }^{19}$ with the support of NVivo software (v 8; QSR International, Melbourne, Australia). Three researchers (LDA, SLH, and HMLY) carried out the initial coding of all transcripts. Analysis followed six stages, as outlined by Braun and Clarke: ${ }^{19}$ (1) familiarization with data, (2) generating initial codes, (3) searching for themes, (4) reviewing themes, (5) defining and naming themes, and (6) producing the report.

The results of the FGs (described in the next section) informed content refinement and delivery. The qualitative analysis of this data demonstrated the importance of what emerged as the "who", "when", and "how" of delivery, and these are outlined in detail in Table 2 . The analysis provided clear details about patient preferences regarding receipt of

Table I Demographics of participants attending focus groups

\begin{tabular}{llllll}
\hline & Group & Group & Group & Group & Group \\
& I & $\mathbf{2}$ & $\mathbf{3}$ & $\mathbf{4}$ & $\mathbf{5}$ \\
\hline Participants (n) & 4 & 3 & 6 & 5 & 6 \\
Sex (m:f) & $2: 2$ & $3: 0$ & $3: 3$ & $4: 1$ & $3: 3$ \\
Mean age (years) & 72.75 & 71.33 & 67.83 & 73.80 & 70.00 \\
Mean FEV, (L) & 0.66 & 1.65 & 1.12 & 1.39 & 1.14 \\
Mean FVC & 1.85 & 2.45 & $2.6 \mathrm{I}$ & 3.12 & $2.4 \mathrm{I}$ \\
Mean FEV,FVC & 0.37 & 0.67 & 0.42 & 0.48 & 0.45 \\
Mean BMI & 24.15 & 28.09 & 26.78 & $27.1 \mathrm{I}$ & 28.77 \\
MRC & & & & & \\
2 & & $\mathrm{I}$ & & & 3 \\
3 & 2 & $\mathrm{I}$ & 3 & 2 & 2 \\
4 & $\mathrm{I}$ & $\mathrm{I}$ & 2 & 3 & 1 \\
5 & $\mathrm{I}$ & & $\mathrm{I}$ & & 3 \\
\hline
\end{tabular}

Abbreviations: $\mathrm{BMI}$, body mass index; $\mathrm{FEV}$, forced expiratory volume in I second FVC, forced vital capacity; MRC, Medical Research Council Dyspnoea Scale. 
Table 2 Participant comments from focus groups

\section{Aspect of self-management}

What are the patients' educational needs? What content would patients like to see in the manual?
Comments on the SPACE for COPD manual

Who should deliver self-management?

When is the right time for self-management to be introduced?

How should self-management be delivered?

\section{Participant comments}

\section{COPD/disease process/managing exacerbations}

"I think understanding the disease is important and ... knowing what the long-term effects are likely to be of that condition." (FG5)

"I like to know what's going on here and what's going to happen in the next 10 years." (FG5)

"It's knowing the difference between a chest infection or [if] you haven't got one and you've got this bad breathing, how long do you let that go on for?" (FG4)

"You don't know quite what these flare-ups are." (FG4)

Breathing exercises

"You panic like mad, you can't breathe ... learning to cope with situations like that." (FG4)

Medicines

"There's never any mention about which order to use [the inhalers] in or when to use them." (FG5)

Exercise

"I think, yes, you need that something to prompt you [to exercise] ... just that little something else ... to remind me, so [a] walking diary [would help].” (FG5)

"If you had the walking diary people who did it would fill it in themselves and then once a month or once a quarter [have] you check it." (FG5)

"On your own, you're never sure whether your under-doing it or overdoing it." (FG4)

\section{Nutrition}

"[N]obody's ever actually from a medical point of view said to me you should [eat] this or you should [eat] that." (FG5)

\section{Oxygen therapy}

"I think people need to know about oxygen, the types of oxygens available. I think would be very useful for people who need to know that." (FG5)

\section{Relaxation}

"[Relaxation - ] I think that's an important skill to have." (FG5)

\section{Family and carers}

"[F]amilies, relatives and friends ... they should be aware that the worst thing they can do is panic ..." (FG3)

"You can actually look back on it, so you can actually remind yourself of something." (FGI)

"It's there for you to dip in and out of when things aren't right and then other times you might want to use it to help with exercise and get fitter." (FG4)

"Reading [the case study] and seeing how she's getting on would help me actually see how l'm getting on, see if I'm doing the same sort of thing." (FGI)

"I'm a great believer in diagrams and pictures, pictures particularly. People look at pictures maybe read over text." (FG5)

"I think professionals who know the people, know what the people are capable of, [should] see them again, then you'll be able to see if they've got any better." (FGI)

"[Physiotherapists] know how far we can go and you stop there, or if we're improving then you'll take it a step further, but other people wouldn't do that unless they've had your training." (FGI)

"I haven't got a lot of faith in GPs." (FG4)

“The GP's got to learn about every single illness and this is a specialist site. It doesn't matter how friendly you are with him, you still think is he right or not?" (FG5)

"If they'd given me [the information] say I0-I5 years ago, I would've sat down and read it and l'd known what l'd got to do and what was going to happen to me." (FG4)

"I feel it would help other people who, as you've just said, recently diagnosed with this problem, it would help." (FG2)

“It doesn't matter what age you are, you're going to say I want to do something about this." (FG4)

"The [person] that it would probably lose on it would be somebody that's just been diagnosed with COPD - you give them this [self-management program] and they wouldn't have a clue." (FG5)

"I think you've got to see somebody, because wouldn't it be best for the health care professionals to see the people as well." (FG3)

"Face to face for starters." (FGI)

"I think maybe in a self-management program, perhaps phone calls to people would be a help to try and motivate people, encourage them more." (FGI)

"[Follow-up] couple of times a year or something, just to keep in touch." (FGI)

"I've always felt that face to face is the best, but sometimes we can't always have the best, we have to take second." (FG2)

"I feel it's nice if they contact you, because at the end of the day they're taking your health and they're thinking about your health, and it's nice to know that there's - apart from your own surgery - that there's someone else thinking about you and just checking that everything's all right." (FG3)

Abbreviations: COPD, chronic obstructive pulmonary disease; FG, focus group; GP, general practitioner; SPACE for COPD, Self-management Programme of Activity, Coping and Education for Chronic Obstructive Pulmonary Disease. 
such an intervention, such as who should deliver the selfmanagement, where it should be received, and what would be liked in an intervention.

Following, the main themes from the data are discussed, covering the content and delivery of the self-management program.

\section{Educational needs}

Various education needs were discussed in the FGs (Table 2). Patients identified or confirmed a variety of education topics important when living with a lung condition, including understanding lung disease, controlling breathlessness, managing anxiety and relaxation techniques, chest clearance, recognizing symptoms of an exacerbation and its subsequent management, energy conservation, managing medication, managing relationships (and sex), and healthy eating. No new topics emerged from the FGs that were not already covered in the prototype manual. Preference was expressed for the content to be divided into stages with dividers and tabs clearly marking the different sections instead of one large unstructured manual. The draft manual was shown to patients toward the end of each FG and the comments were favorable (Table 2). Participants commented that the manual was well presented, clear, and informative. The case studies were recognized as being important to provide opportunities for patients to normalize their experiences and learn through peer comparisons. It was agreed by all participants that the manual was a valuable resource.

\section{Who should deliver self-management?}

Discussions on this topic focused on the need for the health care professional to be knowledgeable about COPD and physical activity. The importance of knowing the patient and their capabilities were also emphasized. Interestingly, a number of participants suggested that the general practitioner (GP) was probably not the right person to deliver the intervention.

\section{When is the right time?}

In relation to the timing of the self-management program, participants unanimously agreed that they would have preferred to receive information about their disease early. Some felt the information should be staggered for an individual with a new diagnosis, but others felt that it was important to receive as much education as possible at the earliest opportunity.

\section{How should self-management be delivered?}

There was a preference for face-to-face contact with a health care professional to introduce and go through the manual.
There was no clear preference expressed for whether the manual was delivered in one face-to-face meeting or over several appointments, despite this being a predefined interview question posed to the group. However, there was consistency in terms of participants wanting telephone contact and follow-up.

\section{Final product: SPACE for COPD}

The FG data were used to refine the education component of the self-management program and inform decisions regarding the extent of health care professional involvement when delivering and supporting this self-management intervention. The completed manual is divided into four stages and 176 pages long, providing an exercise program and covering all the education topics outlined in Table 3, with goal-setting text, case studies for peer modeling, and activities to encourage problem solving and support behavior change. The manual appendix contains information that was not considered necessarily relevant to all participants; for example, information on smoking cessation and oxygen therapy. Feedback received from FG participants indicated that photographs should be used throughout rather than cartoon-based illustrations. "Top tips" were added throughout the manual; these largely comprise advice collected from individuals with COPD or quick summaries of key issues. In relation to the action plan, FG participants expressed a preference for a single sheet of A4-sized paper, preferably with a sputum color chart. The content (and the action plan) was submitted to the Plain English Campaign and, after several editing rounds, the content was approved by the Plain English Campaign and the Crystal Mark for clarity of British English was awarded. This award is given to documents expressing the clearest possible information written in everyday English language. For the purpose of the pilot study, the SPACE manual was professionally produced and printed.

\section{Pilot intervention study}

Once the SPACE for COPD program had been developed, a pilot study was conducted to assess the effectiveness of the approach. Willing primary care sites from a local COPD network were identified.

Patients from five COPD registers in primary care located in city (one in Coventry and one in Leicester) and county (three in Leicestershire) domains in the UK were posted information about the study to meet a convenience sample of 20 patients completing a 6-week follow-up. These registers are held by each GP practice and identify every patient at a practice with a confirmed diagnosis of COPD. Participants who expressed an interest in the study were invited to an initial 
Table 3 Outline of the content of the Self-management Programme of Activity, Coping and Education for Chronic Obstructive Pulmonary Disease (SPACE for COPD)

\begin{tabular}{|c|c|}
\hline SPACE for COPD content & $\begin{array}{l}\text { Self-management } \\
\text { activity/skill }\end{array}$ \\
\hline \multicolumn{2}{|l|}{ Stage I } \\
\hline What's happened to your lungs? & Medical management \\
\hline \multirow[t]{2}{*}{ Exercise: how to get fitter } & Problem solving \\
\hline & Forming partnership \\
\hline Setting your goals & Taking action \\
\hline \multirow[t]{2}{*}{ Managing your stress } & Emotional management \\
\hline & Problem solving \\
\hline Your emotions & Emotional management \\
\hline Controlling your breathing & Medical management \\
\hline \multirow[t]{2}{*}{ Your medication } & Medical management \\
\hline & Problem solving \\
\hline \multicolumn{2}{|l|}{ Stage 2} \\
\hline How to stay fit & Decision making \\
\hline Avoiding and managing & Problem solving \\
\hline days when you feel unwell & Medical management \\
\hline \multirow[t]{2}{*}{ Saving your energy } & Problem solving \\
\hline & Behavioral management \\
\hline The right foods when you feel unwell & Medical management \\
\hline Clearing your chest & Medical management \\
\hline \multicolumn{2}{|l|}{ Stage 3} \\
\hline How to get stronger & Medical/behavioral management \\
\hline \multirow[t]{4}{*}{ Managing your stress } & Emotional management \\
\hline & Taking action \\
\hline & Problem solving \\
\hline & Role management \\
\hline \multirow[t]{3}{*}{ Healthy eating } & Medical management \\
\hline & Decision making \\
\hline & Problem solving \\
\hline \multirow[t]{2}{*}{ Traveling and your lung disease } & Decision making \\
\hline & Problem solving \\
\hline \multicolumn{2}{|l|}{ Stage 4} \\
\hline \multirow[t]{5}{*}{ Staying fit and your hobbies } & Medical/behavioral management \\
\hline & Role management \\
\hline & Decision making \\
\hline & Resource utilization \\
\hline & Taking action \\
\hline \multirow[t]{3}{*}{ Your relationships } & Role management \\
\hline & Emotional management \\
\hline & Problem solving \\
\hline \multirow[t]{2}{*}{ Dealing with setbacks } & Taking action \\
\hline & Problem solving \\
\hline \multirow[t]{3}{*}{ Sex and your lungs } & Emotional management \\
\hline & Role management \\
\hline & Problem solving \\
\hline \multirow[t]{2}{*}{ Breathe easy } & Role management \\
\hline & Resource utilization \\
\hline \multicolumn{2}{|l|}{ Appendix } \\
\hline Frequently asked questions & Problem solving \\
\hline Setting your walking speed & Problem solving \\
\hline \multirow[t]{2}{*}{ Help for carers } & Role management \\
\hline & Emotional management \\
\hline \multirow[t]{2}{*}{ Advice about oxygen } & Medical management \\
\hline & Decision making \\
\hline Information about your medication & Medical management \\
\hline
\end{tabular}

(Continued)
Table 3 (Continued)

\begin{tabular}{ll}
\hline SPACE for COPD content & $\begin{array}{l}\text { Self-management } \\
\text { activity/skill }\end{array}$ \\
\hline Action plan & Resource utilization \\
& $\begin{array}{l}\text { Forming partnership } \\
\text { Decision making }\end{array}$ \\
Case studies & Role management \\
\hline
\end{tabular}

visit, during which written informed consent was obtained and a baseline assessment completed. Spirometry was carried out according to British Thoracic Society guidelines ${ }^{20}$ and demographic data were collected. Outcome measures are described following.

\section{Patient selection}

Patients were eligible to take part if they: had a diagnosis of COPD confirmed by spirometry with a forced expiratory volume in 1 second $\left(\mathrm{FEV}_{1}\right)$ /forced vital capacity (FVC) ratio of $<70 \%$; had a score of 2-5 on the Medical Research Council Dyspnoea Scale; ${ }^{21}$ were not significantly affected by neurological, locomotive, or cognitive problems that would compromise the outcome measures; and had not undertaken PR in the previous 12 months. Participation in other forms of formal education was not considered a criterion for exclusion; however, no patients had participated in education aside from PR.

\section{Delivery of manual}

To pilot the manual as part of a standardized self-management program, an initial consultation with telephone follow-up from a health care professional was the chosen mode of delivery. After baseline measurements were obtained, participants were introduced to the SPACE for COPD program by a trainee health psychologist with clinical experience in COPD and PR and competency in motivational interviewing (LDA). This individualized induction to the program lasted approximately 1 hour and incorporated a discussion regarding the participant's readiness to start a self-management program in support of a healthy lifestyle (which included an exercise program) and explored immediate education needs. Selfefficacy was supported by goal setting and problem solving encouraged. At this stage, the action plan for exacerbation management was also completed. Normal symptoms and indicators of a flare-up were discussed using the action plan and sputum color chart, and participants were encouraged to follow the advice on the action plan if they were concerned they were experiencing a flare-up of symptoms. This did not include provision of a rescue supply of antibiotics and 
steroids by the study team, although there was discussion with participants about self-administration and requesting rescue medication from their primary care physician.

\section{Outcome measures}

Outcome measures were recorded at baseline and after 6 weeks. They included the Self-Reported Chronic Respiratory Disease Questionnaire (CRQ-SR), ${ }^{22}$ Incremental Shuttle Walk Test (ISWT), ${ }^{23}$ Endurance Shuttle Walk Test (ESWT),${ }^{24}$ and Hospital Anxiety and Depression Scale (HADS). ${ }^{25}$ Outcome measurement was conducted by a health care professional not involved in the administration of the manual.

\section{Intervention}

The manual is divided into four stages and participants were advised how to progress through the various educational topics. The exercise program was progressed by participants as they moved through the stages of the manual, and went on to incorporate a modest resistance-training program. The home exercise program advised bouts of exercise most days of the week and the strength-training program three times a week. The speed and duration of walking was prescribed based on results from the ESWT. Participants were advised to purchase a stopwatch, time their walks with this, and keep a record of their progress in a walking diary within the manual. Additionally, each stage of the manual includes information to be learned, such as that on diet, medicine management, and stress management, with tables and interactive tasks for participants to complete to promote knowledge and skill acquisition.

Each patient was further supported by two motivational telephone calls made and documented by the same individual delivering the intervention (LDA) at weeks 2 and 4 . The calls followed a set protocol of questions and responses were recorded for each individual on a case report form. Further discussion was allowed depending on the participant's needs. The telephone calls were of approximately 10 minutes duration and aimed to support the participant through their exercise program and their self-efficacy in self-managing their COPD. Participants also had a contact telephone number for the research team and were able to ring the team if necessary.

In addition to the program, participants continued to receive their usual care from their GP. This care varied according to individual practice and was not directly influenced by the research team. Participants were instructed to continue to use GP services as would be normal for them and that no additional appointments with their GP were required due to participation in the study. GPs were informed of a patient starting the study and provided with an outcome report following their follow-up assessment.

\section{Statistical analysis}

Statistical analysis was completed using PASW statistical software (v 18; IBM, Armonk, NY, USA). The mean difference and $95 \%$ confidence interval $(\mathrm{CI})$ between baseline and 6 weeks were calculated for all outcome measures. Significance level was set at $P<0.05$.

\section{Results \\ Study population}

Thirty-seven participants were recruited to the pilot study and undertook the SPACE for COPD program. Baseline characteristics are presented in Table 4. At 6 weeks, 20 participants attended for follow-up. Of the remainder, five were unable to attend their follow-up appointment due to comorbidities,

Table 4 Baseline demographics of participants in the pilot intervention study

\begin{tabular}{|c|c|}
\hline & SPACE for COPD $(n=37)$ \\
\hline Sex (m:f) & $22: 15$ \\
\hline Mean age (years) & 68.05 \\
\hline Mean FEV $(\mathrm{L})$ & 1.47 \\
\hline Mean FVC (L) & 2.73 \\
\hline Mean FEV/FVC Ratio & 0.54 \\
\hline Mean BMI $\left(\mathrm{kg} / \mathrm{m}^{2}\right)$ & 29.92 \\
\hline Married (n) & 24 \\
\hline \multicolumn{2}{|l|}{ Employment (n [\%]) } \\
\hline Retired & $31(83)$ \\
\hline Working & $5(14)$ \\
\hline Long-term sick leave & I (3) \\
\hline \multicolumn{2}{|l|}{ Smoking (n [\%]) } \\
\hline Current smoker & $3(8)$ \\
\hline Previously & $31(84)$ \\
\hline Nonsmoker & $3(8)$ \\
\hline LTOT (n [\%]) & $2(5)$ \\
\hline \multicolumn{2}{|l|}{ MRC (n [\%]) } \\
\hline 2 & $16(43)$ \\
\hline 3 & $12(32)$ \\
\hline 4 & $7(19)$ \\
\hline 5 & $2(5)$ \\
\hline \multicolumn{2}{|l|}{ Comorbidities (n [\%]) } \\
\hline Diabetes & $6(16)$ \\
\hline Ischemic heart disease & I (3) \\
\hline Hypertension & $16(43)$ \\
\hline Heart failure & I (3) \\
\hline Arthritis & $12(32)$ \\
\hline Depression & $2(5)$ \\
\hline
\end{tabular}


three due to COPD-related ill health, five did not attend/were lost to follow-up, one died, and two perceived themselves too fit to follow the exercise program. Participants received their scheduled telephone calls, but participants made no phone calls to the team supporting the intervention, despite this service being offered at the initial consultation.

\section{Pilot study of the SPACE manual in primary care}

Statistical analysis was completed using statistical software (PASW 18, Chicago, IL, USA). Paired $t$-tests were carried out and Table 5 shows the baseline and mean change results of the CRQ-SR, HADS, ISWT, and ESWT measurements. Statistically significant improvements were observed for the dyspnea domain of the CRQ-SR and ESWT. There was a mean change in dyspnea of 0.67 (95\% CI 0.23 to 1.11 , $P=0.005)$, which also exceeds the minimum clinically important difference of 0.5. ESWT performance increased by 302.25 seconds (95\% CI 161.47 to $443.03, P<0.001)$.

\section{Discussion}

As far as we are aware, this is the first report of a COPD self-management intervention that discusses the development of the intervention and demonstrates how it relates to the development of core self-management skills. During the development of the intervention, data from the FGs helped to identify a wealth of education topics and demonstrated patients' preference for some face-to-face contact in the initial stages of the intervention. Participants that went on to trial the intervention demonstrated the feasibility of the approach, with improvements seen in dyspnea and exercise performance.

Table 5 Baseline and mean change with 95\% confidence intervals (Cls) for the Self-Report Chronic Respiratory Questionnaire (CRQ-SR), Incremental ShuttleWalkTest (ISWT), Endurance Shuttle Walking Test (ESWT), and the anxiety (A) and depression (D) domains of the Hospital Anxiety and Depression Scale (HADS)

\begin{tabular}{llll}
\hline Measure & Baseline & Mean change $(95 \% \mathrm{CI})$ & $\boldsymbol{P}$ \\
\hline $\begin{array}{llll}\text { CRQ-SR* } \\
\text { Dyspnea }\end{array}$ & 3.15 & $0.67(0.23$ to I.II $)$ & 0.005 \\
Fatigue & 4.04 & $0.14(-0.6 \mathrm{I}$ to 0.90$)$ & $0.70 \mathrm{I}$ \\
$\quad$ Emotion & $5.0 \mathrm{I}$ & $0.32(-0.24$ to 0.87$)$ & 0.244 \\
$\quad$ Mastery & 5.54 & $0.2 \mathrm{I}(-0.36$ to 0.78$)$ & 0.444 \\
ISWT (meters) & 316.00 & $29.00(-3.53$ to $6 \mathrm{I} .0)$ & 0.780 \\
ESWT (seconds) & 240.70 & $302.25(\mathrm{I} 6 \mathrm{I} .47$ to 443.03$)$ & $<0.00 \mathrm{I}$ \\
HADS-A & $7.3 \mathrm{I}$ & $-\mathrm{I} .73(-3.26$ to $-0.2 \mathrm{I})$ & 0.280 \\
HADS-D & 4.79 & $-0.2 \mathrm{I}(-\mathrm{I} .39$ to 0.97$)$ & $0.7 \mathrm{II}$ \\
\hline
\end{tabular}

Note: *A change of 0.5 denotes a meaningful clinically important difference.
Lorig and Holman ${ }^{11}$ outline that self-management education should be tailored to address patients' concerns and problems; for individuals with COPD, this is predominately chronic dyspnea, the impact of which is well-documented. ${ }^{26}$ During the development of this intervention, we strived to include opportunities for patients to develop the necessary skills and knowledge to best manage their disease through written activities; for example, one such activity involved asking patients to review their goal-setting activities and to consider what did and did not go well with the activity as a form of problem solving.

The FG data also highlighted the importance of selfmanagement, the content desired, and patients' preferred mode of delivery, which confirmed the perceived value and benefit that face-to-face contact has in providing supported self-management. Among the education topics discussed by patients, advance care planning was not identified, so was not added to the program for the pilot study. Patients also identified who they considered important in delivering self-management, with the consensus being that a health care professional with both disease knowledge and personal knowledge of the individual would be best. Interestingly, the GP was not identified as the most appropriate individual to support the self-management program. Patients also touched on the potential benefits of having peer support when following such a program and this is one advantage to programs such as PR. ${ }^{27}$ Although SPACE for COPD was initially delivered without such peer contact, facilitating this may be feasible and enhance benefits in outcomes not seen in this study, such as mastery.

The results of the pilot study indicate that the delivery of a low intensity manual-based self-management program for COPD is feasible and worthy of further inspection. Delivery of the SPACE for COPD in this cohort provoked important changes in exercise performance and dyspnea. However, as this population demonstrated very low levels of depression, there was reduced scope to explore the effects of the program on depression. In contrast, anxiety levels were greater in this cohort than have been observed for depression and improved by 1.73 points on the HADS scale, which was an important clinical change but did not reach statistical significance. The mastery domain of the CRQ was also high at baseline. "Mastery" is a measure of one's control over one's disease and symptoms. This high sense of control might be a feature of this population, the members of which are largely managed in primary care, so a significant change was not observed. There was also a small increase (29 meters) in the ISWT, which was encouraging. 
However, the results were limited due to the low attendance rate seen at 6-week follow-up. This was partly due to COPD-related ill health; those affected participants advised that they had been continuing with the intervention during telephone contacts but were unable to attend at the hospital for outcome measures. Unfortunately, we were unable to distinguish between those who may have continued to follow the program and failed to attend the 6-week appointment and those who simply discontinued the intervention.

Participants that did experience an exacerbation predominantly contacted their GP in the first instance and did not always inform the study team. This highlights that in the case of flare-ups of their condition, these patients already felt confident to make decisions and take action. In the case of comorbidities, arthritis was the main reason cited for discontinuing the exercise program.

The anticipated results of a self-management study in milder disease might be maintenance and the prevention of decline. For this pilot study, we anticipated that this might be the case and that patients recruited from primary care would present with minimal disability. Although the participants were much less disabled than a population recruited for a PR program, they were more affected by their disease than we anticipated, as reflected by exercise performance measures.

The combined benefit of improved dyspnea and exercise performance is an encouraging but not necessarily consistently reported finding for self-management approaches in COPD for populations similar to those in this current study. A randomized controlled trial with blinded outcomes and a longer period of follow-up is clearly needed to confirm these findings. SPACE for COPD was initially piloted in written English; however, following evidence from a definitive randomized controlled trial, the program could be translated into other languages to increase its scope of use.

The most frequently cited studies examining self-management in COPD have reported varying effects on exercise capacity and quality of life. ${ }^{3,5,6,10}$ The differences in protocols and target groups inevitably make comparisons difficult, as highlighted by the Cochrane Review examining the benefit of self-management in COPD. ${ }^{7}$ One earlier report of self-management that has some similarities to this current study was based around an information brochure and an action plan. ${ }^{10}$ Although the contact time with a health care professional of this program was broadly similar to that in the current study, the breadth of information in the current SPACE manual is much greater and has an embedded exercise component. Of the more recent studies, the most notable are the COPE self-management studies ${ }^{3,6}$ and Living Well with COPD, ${ }^{5}$ both of which were larger and had much greater levels of health care contact than this current pilot study.

The aim of the COPE studies was to assess the effect of an intense self-management approach with an exercise component on exercise performance and quality of life in stable patients. Overall the, COPE I study was unable to document any benefit to self-management, ${ }^{6}$ although a qualitative evaluation reported a more positive impact of the intervention. ${ }^{28}$ COPE II, ${ }^{3}$ following a similar program to COPE I but with a much more intense exercise program, reported a positive impact on exercise performance. The exercise program, which was for up to 12 months, was largely supervised, compared with the unsupervised SPACE for COPD program. The Living Well with COPD program favorably influenced readmissions in a group whose members had experienced an exacerbation who had required hospitalization in the previous 12 months; as such, these patients probably represent a different cohort of individuals with COPD than that of the current study.

Much of the recent literature has explored the impact of a self-management approach either at or around the time of an acute exacerbation, but this was not the purpose of the current study. We recruited a group of participants almost exclusively managed in primary care, with the aim of promoting and maintaining a healthy lifestyle in patients, supported by a structured and standardized self-management program. However, we are mindful that with the study recruitment there is the possibility of a bias in participants who volunteer compared to those who do not respond or decline to participate.

An important component of the SPACE for COPD study was the utilization of MI to foster behavior change. Although the impact of individual components of such a comprehensive intervention cannot be examined in isolation, there is evidence to suggest that the effects of MI are enhanced and sustained when added to an active treatment. ${ }^{29}$

\section{Conclusion}

This paper has described the development of a selfmanagement program, SPACE for COPD, which identifies core strategies needed for successful self-management. Pilot study data examining this approach indicate that the approach is effective in changing exercise tolerance and dyspnea. As far as we are aware, this is the first self-management program to demonstrate how the content of the intervention relates to the core skills of self-management. The combined benefit of improved quality of life and exercise performance seen in 
this cohort is encouraging and offers a novel standardized approach to self-management.

\section{Acknowledgments}

The authors would like to thank Dr Nicky Hudson for assistance in reviewing this paper.

The research was supported by the National Institute for Health Research (NIHR) Collaborations for Leadership in Applied Health Research and Care based at the University Hospitals of Leicester National Health Service (NHS) Trust. The views expressed are those of the authors and not necessarily those of the NHS, the NIHR, or the Department of Health.

\section{Disclosure}

The early development of SPACE for COPD was in part supported by a Trevor Clay Memorial Grant awarded by the British Lung Foundation. The authors declare no other conflicts of interest in this work.

\section{References}

1. Davies MJ, Heller S, Skinner TC, et al; Diabetes Education and Self Management for Ongoing and Newly Diagnosed Collaborative. Effectiveness of the diabetes education and self management for ongoing and newly diagnosed (DESMOND) programme for people with newly diagnosed type 2 diabetes: cluster randomised controlled trial. BMJ. 2008;336(7642):491-495.

2. Lewin B, Robertson IH, Cay EL, Irving JB, Campbell M. Effects of self-help post-myocardial-infarction rehabilitation on psychological adjustment and use of health services. Lancet. 1992;339(8800): 1036-1040.

3. Effing T, Zielhuis G, Kerstjens H, van der Valk P, van der Palen J. Community based physiotherapeutic exercise in COPD selfmanagement: a randomised controlled trial. Respir Med. 2011;105(3): 418-426.

4. Gallefoss F. The effects of patient education in COPD in a 1-year follow-up randomised, controlled trial. Patient Educ Couns. 2004;52(3): 259-266.

5. Bourbeau J, Julien M, Maltais F, et al; Chronic Obstructive Pulmonary Disease axis of the Respiratory Network Fonds de la Recherche en Santé du Québec. Reduction of hospital utilization in patients with chronic obstructive pulmonary disease: a disease-specific self-management intervention. Arch Intern Med. 2003;163(5):585-591.

6. Monninkhof E, van der Valk P, van der Palen J, van Herwaarden C, Zielhuis G. Effects of a comprehensive self-management programme in patients with chronic obstructive pulmonary disease. Eur Respir J. 2003;22(5):815-820.

7. Effing T, Monninkhof EM, van der Valk PD, et al. Self-management education for patients with chronic obstructive pulmonary disease. Cochrane Database Syst Rev. 2007;(4):CD002990.

8. McGeoch GR, Willsman KJ, Dowson CA, et al. Self-management plans in the primary care of patients with chronic obstructive pulmonary disease. Respirology. 2006;11(5):611-618.
9. Martin IR, McNamara D, Sutherland FR, Tilyard MW, Taylor DR. Care plans for acutely deteriorating COPD: a randomized controlled trial. Chron Respir Dis. 2004;1(4):191-195.

10. Watson PB, Town GI, Holbrook N, Dwan C, Toop LJ, Drennan CJ. Evaluation of a self-management plan for chronic obstructive pulmonary disease. Eur Respir J. 1997;10(6):1267-1271.

11. Lorig KR, Holman H. Self-management education: history, definition, outcomes, and mechanisms. Ann Behav Med. 2003;26(1):1-7.

12. Coultas D, Frederick J, Barnett B, Singh G, Wludyka P. A randomized trial of two types of nurse-assisted home care for patients with COPD. Chest. 2005;128(4):2017-2024.

13. Miller W, Rollnick S. Motivational Interviewing: Preparing People for Change, 2nd ed. New York, NY: Guilford Press; 2002.

14. Lomundal BK, Steinsbekk A. Observational studies of a one year self-management program and a two year pulmonary rehabilitation program in patients with COPD. Int J Chron Obstruct Pulmon Dis. 2007;2(4):617-624.

15. Ninot G, Moullec G, Picot MC, et al. Cost-saving effect of supervised exercise associated to COPD self-management education program. Respir Med. 2011;105(3):377-385.

16. Trappenburg JC, Koevoets L, de Weert-van Oene GH, et al. Action Plan to enhance self-management and early detection of exacerbations in COPD patients; a multicenter RCT. BMC Pul Med. 2009;9:52.

17. Khdour MR, Kidney JC, Smyth BM, McElnay JC. Clinical pharmacyled disease and medicine management programme for patients with COPD. Br J Clin Pharmacol. 2009;68(4):588-598.

18. Clark N, Becker M, Janz N, Lorig K, Rakowski W, Anderson L. Self-management of chronic disease by older adults. J Aging Health. 1991;3(1):3.

19. Braun V, Clarke V. Using thematic analysis in psychology. Qual Res Psychol. 2006;3(2):77-101.

20. Bellamy D, Booker R, Connellan S, Halpin D; BTS COPD Consortium. Spirometry in Practice: A Practical Guide to using Spirometry in Primary Care, 2nd ed. London: BTS COPD Consortium; 2005.

21. Fletcher CM, Eimes PC, Fairbairn et al. The significance of respiratory symptoms and the diagnosis of chronic bronchitis in a working population. BMJ. 1959;2;257-266.

22. Williams JE, Singh SJ, Sewell L, Guyatt GH, Morgan MD. Development of a self-reported Chronic Respiratory Questionnaire (CRQ-SR). Thorax. 2001;56(12):954-959.

23. Singh SJ, Morgan MD, Scott S, Walters D, Hardman AE. Development of a shuttle walking test of disability in patients with chronic airways obstruction. Thorax. 1992;47(12):1019-1024.

24. Revill SM, Morgan MD, Singh SJ, Williams J, Hardman AE. The endurance shuttle walk: a new field test for the assessment of endurance capacity in chronic obstructive pulmonary disease. Thorax. 1999; 54(3):213-222.

25. Zigmond AS, Snaith RP. The hospital anxiety and depression scale. Acta Psychiatr Scand. 1983;67(6):361-370.

26. Nici L, Donner C, Wouters E, et al; ATS/ERS Pulmonary Rehabilitation Writing Committee. American Thoracic Society/European Respiratory Society statement on pulmonary rehabilitation. Am J Respir Crit Care Med. 2006;173(12):1390-1413.

27. Arnold E, Bruton A, Ellis-Hill C. Adherence to pulmonary rehabilitation: A qualitative study. Respir Med. 2006;100(10):1716-1723.

28. Monninkhof E, van der Aa M, van der Valk P, et al. A qualitative evaluation of a comprehensive self-management programme for COPD patients: effectiveness from the patients' perspective. Patient Educ Couns. 2004;55(2):177-184.

29. Hettema J, Steele J, Miller WR. Motivational interviewing. Annu Rev Clin Psychol. 2005;1:91-111. 
International Journal of COPD

\section{Publish your work in this journal}

The International Journal of COPD is an international, peer-reviewed journal of therapeutics and pharmacology focusing on concise rapid reporting of clinical studies and reviews in COPD. Special focus is given to the pathophysiological processes underlying the disease, intervention programs, patient focused education, and self management protocols.

This journal is indexed on PubMed Central, MedLine and CAS. The manuscript management system is completely online and includes a very quick and fair peer-review system, which is all easy to use. Visit http://www.dovepress.com/testimonials.php to read real quotes from published authors.

Submit your manuscript here: http://www.dovepress.com/international-journal-of-copd-journal 